\title{
Mercury Removal from Flue Gas by Aqueous Precipitation
}

\author{
Feng Jiang (Corresponding author) \\ Mechanical and Aerospace Engineering, Henry Samueli School of Engineering \\ University of California-Irvine, United States \\ 26150 Laguna Ct., Apt 218, Laguna Hills, CA 92656, USA \\ Tel: 949-861-0611_E-mail: fjiang2@uci.edu
}

\begin{abstract}
Randy Seeker
Mechanical and Aerospace Engineering, Henry Samueli School of Engineering University of California-Irvine, United States also Calera Corporation

Tel: 949-824-8191Ｅ-mail: randy.seeker@uci.edu
\end{abstract}

Derek Dunn-Rankin

Mechanical and Aerospace Engineering, Henry Samueli School of Engineering University of California-Irvine, United States

Tel: 949-824-8745Ｅ-mail: ddunnran@uci.edu

Received: April 7, 2015 Accepted: April 27, 2015

doi:10.5296/emsd.v4i1.7393 URL: http://dx.doi.org/10.5296/emsd.v4i1.7393

\begin{abstract}
Mercury has drawn the public's concern due to its bio-accumulative nature and its adverse impact on human health. At the same time, concern for greenhouse gas release has also grown, leading to a range of carbon capture strategies. Previous mercury removal studies, however, focused on either dry techniques or acidic solution conditions, and a major uncertainty is how high alkalinity (which is used in carbon mineralization capture methods) may result in a different mercury removal mechanism. To examine this question in detail, in this study, a lab-scale liquid-gas scrubbing system is manufactured and installed, based on the
\end{abstract}


carbon mineralization by aqueous precipitation (CMAP) process for $\mathrm{CO}_{2}$ sequestration. Sodium hydroxide solution is selected as a typical candidate to remove mercury. Based on the test results, the CMAP process, like most other capture methods, has relatively low elemental mercury removal efficiency, i.e. less than $20 \%$, but it can remove oxidized mercury with more than $90 \%$ efficiency. This performance is very similar to that of the traditional flue gas desulfurization processes which are operated under acidic conditions, at $\mathrm{pH}$ from 4 to 6 . Equilibrium calculations by Visual MINTEQ predict the speciation of mercury equilibrium in the liquid phase, and the result is in agreement with the experimental findings.

Keywords: Mercury, Flue gas, $\mathrm{CO}_{2}$ sequestration, Aqueous precipitation, Alkalinity

\section{Introduction}

\subsection{Mercury}

Mercury is widely used in thermometers, barometers, manometers, and other scientific apparatus. It is also present in the flue gas from power plants that burn fossil fuel (mainly coal), where its toxicity has drawn public attention. A study in Japan measured $0.066 \mathrm{ppm}$ mercury content in coal from USA, Australia, South Africa, China and Japan (Yokoyama, 2000). As part of the Information Collection Request (ICR) process of USEPA, over 40,000 coal samples were analyzed and the mercury content ranged from 0.0449 to $0.126 \mathrm{ppm}$ (Pavlish, 2003). Although mercury is naturally present in only trace concentrations in coal, the extraordinary mass of this fuel that is burned to satisfy U.S. and worldwide energy demands leads to a substantial emission of mercury. Hence, controlling of mercury emissions is extremely important. Moreover, with the increased sensitivity to global climate change, integrated control strategies that target greenhouse gas emissions and multiple pollutants, such as $\mathrm{CO}_{2}$ and mercury, may be cost-effective. Aqueous carbonate mineral sequestration processes represent one such potential integrated control strategy. The direct sequestration of $\mathrm{CO}_{2}$ into solid phases using mineralization is a potentially effective method to remove $\mathrm{CO}_{2}$ from flue gas, and the principal objective of this study is to determine if this method can also be considered an effective integrated strategy for the simultaneous capture of mercury.

Mercury occurs naturally in the environment and exists in a large number of chemical forms. In pure form, it is known alternatively as "elemental" or "metallic" mercury (also expressed as $\mathrm{Hg}(0)$ or $\left.\mathrm{Hg}^{0}\right)$. Most of the mercury in the atmosphere is in the form of elemental mercury vapor, which circulates for up to a year, and hence can be widely dispersed (Mercury Study Report to Congress, Volume I, December 1997). Mercury can be bound to other compounds as monovalent or divalent mercury (also expressed as $\mathrm{Hg}(\mathrm{I})$ or $\mathrm{Hg}_{2}{ }^{2+}$ and $\mathrm{Hg}$ (II) or $\mathrm{Hg}^{2+}$, respectively). Many inorganic and organic compounds of mercury can be formed from $\mathrm{Hg}$ (II), which is the most common oxidation state of mercury and exists in a higher ratio than $\mathrm{Hg}(\mathrm{I})$ in the environment.

Mercury speciation refers to the partitioning of $\mathrm{Hg}$ into $\mathrm{Hg}^{0}, \mathrm{Hg}^{2+}$ and $\mathrm{Hg}_{\mathrm{p}}$ (particulate mercury). The speciation plays an important part in mercury's toxicity to living organisms. Speciation also influences the transport of mercury within and between environmental compartments. Moreover, and most important for this study, speciation is very crucial for the 
controllability of mercury emissions to the air. Mercury exists in coal combustion flue gas in two main forms: elemental mercury $\left(\mathrm{Hg}^{0}\right)$ and oxidized state $\left(\mathrm{Hg}^{2+}\right)$. One study showed that about $50 \%$ of mercury emissions from typical coal combustion power plants is in the elemental form and $40 \%$ in the oxidized form (Global mercury assessment. United Nations Environment Programme, Chemicals., 2002). Because there is such difficulty capturing elemental mercury, one obvious approach to mercury emission control would be to control the mercury speciation in the combustion process directly. Because mercury is so volatile, this is non-trivial, as described next.

Recent studies on mercury speciation, including the EPA ICR boiler tests; indicate that high levels of mercury oxidation are most strongly correlated with high chlorine concentrations in coal, demonstrating that chlorination is a predominant oxidation mechanism (Pavlish, 2003). When $\mathrm{Hg}$ enters the flue gas cleaning devices, it is present as a mixture of $\mathrm{Hg}_{\mathrm{p}}$ (particulate mercury), $\mathrm{Hg}^{2+}$, and $\mathrm{Hg}^{0}$. In the presence of $\mathrm{Cl}$, gas-phase equilibrium conditions favor the formation of $\mathrm{HgCl}_{2}$ at flue gas cleaning temperatures. However, the oxidation of $\mathrm{Hg}^{0}$ is kinetically limited by the homogeneous and heterogeneous reaction rates (Kolker, 2006). High coal chlorine contents have been shown to correlate with higher levels of mercury oxidation and retention. For low chlorine coals such as subbituminous and lignite, chlorine or chloride injection into the flame zone could be a viable option to promote elemental mercury oxidation in the post flame zone as the flue gas cools down (Tan, 2004). HCl, however, appears to have little significance in mercury speciation at concentrations and temperatures typically found in ESPs and bag houses (Laudal, 2000).

Controlling mercury emissions through end-of-pipe techniques, such as exhaust gas filtering, may be especially appropriate to raw materials with trace mercury contamination, including fossil fueled power plants (Global mercury assessment. United Nations Environment Programme, Chemicals., 2002). Existing control technologies that reduce $\mathrm{SO}_{2}, \mathrm{NO}_{\mathrm{x}}$ and $\mathrm{PM}$ for coal-fired boilers and incinerators also yield some level of mercury control. For coal-fired boilers, reductions range from 0 to 96 percent, depending on coal type, boiler design, and emission control equipment. In the long run, integrated control strategies that target multiple pollutants including $\mathrm{CO}_{2}, \mathrm{SO}_{2}, \mathrm{NO}_{\mathrm{x}}, \mathrm{PM}$ and mercury may be a cost-effective approach. For instance, in a 25-year mercury study in the Netherlands, it appears that on average $50 \%$ of the mercury is removed in the ESP and $50 \%$ of the remainder is removed in the Flue Gas Desulfurization process (FGD), resulting in a total mercury removal of $75 \%$. If a high-dust selective catalytic reduction ( $\mathrm{SCR}$ for $\mathrm{NO}_{\mathrm{x}}$ reduction) device is present, the total removal can be up to $90 \%$ (Meij, 2006).

It is clear that FGD, as a liquid scrubber, is an effective method to treat mercury in flue gas from coal fired power plants. FGD systems are currently installed on about $25 \%$ of the coal utility generating capacity in the U.S. Because of the significance of FGD at treating mercury in current coal-fired power plants, this technology serves as a baseline for further comparison in this study. In the FGD process, more than a dozen different reagents have been used, with lime and limestone being the most popular. Approximately $78 \%$ of the FGD systems are wet systems using lime or limestone as a reagent (Hance, 1991). Gaseous compounds of $\mathrm{Hg}^{2+}$ are generally water-soluble and can be absorbed in the aqueous slurry of a wet FGD system. 


\section{Mll Macrothink}

Therefore mercury is captured at some base level equivalent to approximately $90 \%$ of the $\mathrm{Hg}^{2+}$ at essentially no cost to the utility (Pavlish, 2003). However, gaseous elemental mercury vapor does not appear to be removed by an FGD system (Clarke, 1992) (Longwell, 1995). This is not surprising since elemental mercury has a very low solubility in water. For units with an existing wet FGD, the mercury removal efficiency obtained has been found to be strongly dependent on the speciated form of the mercury. Tests of mercury removal by FGD systems have shown little or no removal of elemental mercury (Air pollution prevention and control division, U.S. Environmental Protection Agency). It has also been observed that in some FGD systems, a portion of the oxidized mercury absorbed is reduced to produce elemental mercury, which desorbs back into the flue gas (Diaz-Somoano, 2007). This phenomenon, called mercury "re-emission" is believed to be caused by the chemical reduction of oxidized mercury by sulfite/bisulfite ions and/or other ions in the FGD liquor. Re-emissions can thus limit the net capture of oxidized mercury by wet FGD absorbers.

\subsection{Carbonate Mineralization by Aqueous Precipitation}

Among the most promising and potentially viable methods for direct carbon sequestration from fossil fuel combustion are the classes of methods that chemically bond the carbon into a solid matrix rather than exhausting it into the atmosphere. Most such processes attempt to reach an end product of carbonate, which are very stable and can be used in a variety of ways, including fillers for papers and plastics and building materials. This class of carbon capture methods generally relies on $\mathrm{CO}_{2}$ capture and precipitation, which requires extremely efficient gas/liquid contact and the proper chemical balances. One such method and the one that is used as the core example in this study is the Carbonate Mineralization by Aqueous Precipitation (CMAP) developed by Calera (US/Los Gatos Patent No. USPC Class: 423230).

CMAP is designed to sequester $\mathrm{CO}_{2}$ from stacks of industrial processes or energy generating plants using a source of alkalinity and a source of calcium to produce solid carbonates of calcium $(\mathrm{Ca})$. If carefully controlled precipitation conditions are maintained, the calcium carbonate solids can then be used for a wide variety of applications including fillers for paper, plastics, and concrete and directly as cement for applications such as cement fiber boards.

The inputs required for this process are a source of $\mathrm{CO}_{2}$, a source of alkalinity such as produced sodium hydroxide or waste calcium hydroxide and a source of calcium such as geologic brines or waste calcium hydroxide. The chemistry involved in the process is fairly straightforward in concept. At a given $\mathrm{pH}$ the relative amounts of the various carbonate species are all in rapidly attained chemical equilibrium. Carbonate precipitation can occur if the solubility products (Ksp) of the various possible carbonates are exceeded. The solubility product of a carbonate is given by the following expression:

$$
\left[\mathrm{Ca}^{2+}\right]\left[\mathrm{CO}_{3}{ }^{2-}\right]=\mathrm{Ksp}
$$

Where $\left[\mathrm{Ca}^{2+}\right]$ is the concentration (activity) of the calcium cation and $\left[\mathrm{CO}_{3}{ }^{2-}\right]$ is the concentration of the carbonate ion. For example, the precipitation of calcium into solid carbonate from geologic brine will take place under one of two conditions. 


\section{Macrothink}

1. The concentrations of the cation $\mathrm{Ca}^{2+}$ are increased to the point where

$$
\left[\mathrm{Ca}^{2+}\right]\left[\mathrm{CO}_{3}{ }^{2-}\right]>\mathrm{Ksp} \text { of } \mathrm{CaCO}_{3} \text {. }
$$

2. The concentration of $\mathrm{CO}_{3}{ }^{2-}$ is increased to the point where

$$
\left[\mathrm{Ca}^{2+}\right]\left[\mathrm{CO}_{3}{ }^{2-}\right]>\mathrm{Ksp} \text { of } \mathrm{CaCO}_{3}
$$

In the CMAP process the concentration of $\mathrm{CO}_{3}{ }^{2-}$ is increased upon introduction of the stack $\mathrm{CO}_{2}$ because the $\mathrm{pH}$ has been raised through the addition of alkalinity via use of sodium hydroxide or use of dissolved calcium hydroxide to the point where $\mathrm{CO}_{3}{ }^{2-}$ is the dominant and stable species of dissolved carbonate. Then in the case of dissolved calcium hydroxide most or all of the Ca present precipitates as a solid carbonate. In the case of use of sodium hydroxide, the $\mathrm{CO}_{3}{ }^{2-}$ enriched water is contacted in a separate precipitation unit with a source of dissolved calcium such as geologic brine and calcium carbonate will precipitate in the precipitation unit. In either case, by careful control of the chemistry, concentrations and mixing conditions the crystalline structure and particle size of the calcium carbonate precipitant can be controlled in order to generate carbonate with appropriate properties for different applications.

Considering the relatively high solubility of $\mathrm{Hg}^{2+}$, it is expected that the wet scrubbing process inherently involved in the CMAP method can at the same time remove some portion of total mercury. However, since traditional studies of mercury control mainly have focused on either dry techniques for adsorption and capture, or acidic wet environments, it is unclear how the different operational parameters required for CMAP can influence mercury removal in an alkaline environment.

\section{Experimental}

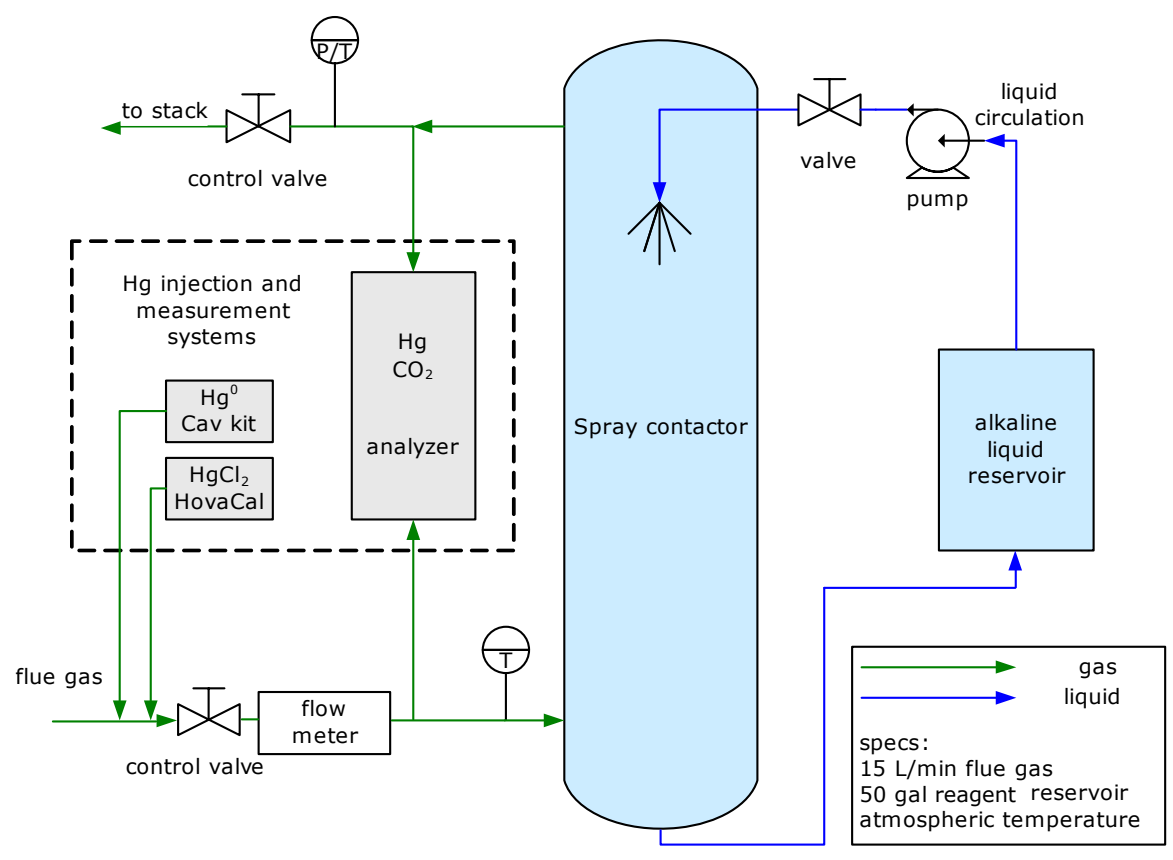

Figure 1 Process Flow Diagram 
The overall mass transfer coefficient was characterized as the key factor during the subscale system design for the current work. Given the same conditions, i.e. solution concentration, gas concentration, liquid and gas flow rate, temperature, pressure and etc., for every finite unit in a full-scale facility compared to the lab-scale setup, identical performance will be suggested by the same overall mass transfer coefficient. The capture of $\mathrm{CO}_{2}$ is similar to the capture of any gases, and so mercury-containing species will experience similar contact transfer processes but with much lower rates because the concentration gradients are much smaller, as are the diffusion coefficients. In order to make sure the test results from this study can be compared to those to be obtained in an industrial scale facility, the overall mass transfer coefficient $(\mathrm{KGaV})$ was derived by employing two-film theory and matched to that typical in full scale systems.

Figure 1 shows the system process flow diagram with the contactor featured prominently. In this study simulated gases were used to ensure better control of the desired gas component concentrations. A 4 inch $(10.16 \mathrm{~cm})$ diameter polyethylene pipe was chosen to construct the scrubber with a diameter ratio (scrubber diameter over packing material diameter) of over 6 , which can promote a better liquid distribution across the packing section. Based on the estimated liquid flow rate $(1.5 \mathrm{~L} / \mathrm{min})$ and gas flow rate $(15 \mathrm{~L} / \mathrm{min})$, a 3 foot long contacting length could provide a gas residence time of 26 seconds, which is comparable with that of a standard FGD process. Along the total 4 foot $(122 \mathrm{~cm})$ long contactor, 3 feet $(91.5 \mathrm{~cm})$ were packed with Pall Ring as packing material for liquid gas contact.

In this study, a countercurrent configuration was chosen for the spray contactor. Flue gas flows upwards inside the contactor and reagent solution is sprayed downwards with nozzles. The nozzle used in this study is from the BETE Company with model number WL3/4. It features a $90^{\circ}$ angle full cone spray pattern. Estimated pressure drop at $1.5 \mathrm{~L} / \mathrm{min}$ is $10 \mathrm{psi}$ and estimated liquid drop size is $268 \mu \mathrm{m}$. Liquid solutions were prepared and stored in a 50-gallon container. A variable frequency controlled stainless steel gear pump was employed to circulate the solution in the spray contactor. In order to protect subsequent instruments, at the top gas exit of the spray contactor there is a water trap to remove excessive moisture from the exiting flue gas. Temperature and pressure are measured to ensure that the system is running at atmospheric temperature and pressure. Mercury and CO2 are sampled at different locations with a standard diaphragm sampling pump with PTFE pump head. In this study $\mathrm{NaOH}$ was used and the analysis of alkaline solution was accomplished with a Titrondo dynamic titration instrument from Metrohm AG and a carbon coulometry instrument. Mercury was added to the total gas stream by two independent mercury injection systems. One is the PSA Cavkit 10.536 mercury calibration system and the other is the HovaCal calibration gas generation system. The Cavkit system has an internal elemental mercury reservoir placed in a temperature controlled oven. The desired amount of mercury is produced by adjusting two mass flow controllers (MFC). One is for carrier gas flowing through the mercury reservoir and the other is a dilution flow. The HovaCal system consists of a peristaltic pump and evaporator. $\mathrm{HgCl}_{2}$ solution, serving as the $\mathrm{Hg}^{2+}$ source, is pumped to a $200^{\circ} \mathrm{C}$ evaporator where it is mixed with carrier air to be injected into the flue gas stream. $\mathrm{Hg}^{2+}$ is determined by the $\mathrm{HgCl}_{2}$ solution concentration, peristaltic pump speed and clean air flow rate. A 


\section{Macrothink}

continuous emission monitoring system (CEMS) measures mercury concentration of the sample gas from the test section. Although it is ultimately reliable and continuous, the CEMS is a fairly complex instrument and one that required a substantial level of maintenance and troubleshooting before it provided reliable results.

\section{Results and Discussion}

As a brief reiteration, the principal objective of this research is to examine the potential for co-capture of $\mathrm{CO}_{2}$ and mercury using precipitation-based strategies, as exemplified by the CMAP process. It is important to recognize that the process cannot be optimized only for mercury capture but must capture mercury under conditions optimized for $\mathrm{CO}_{2}$ capture. Based on the preliminary and extended scrubber characterization experiments, the standard parameters for the following runs have been chosen as $10 \mathrm{~L} / \mathrm{min}$ gas stream, $1.2-1.5 \mathrm{~L} / \mathrm{min}$ liquid stream with recirculation, $0.5 \mathrm{~N}$ of chemicals, room temperature $\left(13-15^{\circ} \mathrm{C}\right)$ and atmospheric pressure, unless otherwise noted. $\mathrm{CO}_{2}$ concentration is designated in every test. In order to evaluate mercury removal with minimal interference, experiments were designed to first run elemental and oxidized mercury, respectively, followed by the mixture of both species.

\subsection{Experimental Results}

Figure 2 shows an example of the data collected from a sample validation process. Validation is needed because when using the Cavkit as an elemental mercury source the concentration given by the software only represents part of the total gas stream. There is also dilution and inevitable loss of mercury to the system by different means, i.e. adsorption to the system hardware surface and possible leakage. When oxidized mercury is involved, much higher losses of mercury can be expected throughout the system since $\mathrm{HgCl}_{2}$ can potentially stick to almost any material surface, including PTFE. Therefore, a sample validation is necessary and one is performed every time after changing the mercury input concentration in order to verify the actual inlet concentration.

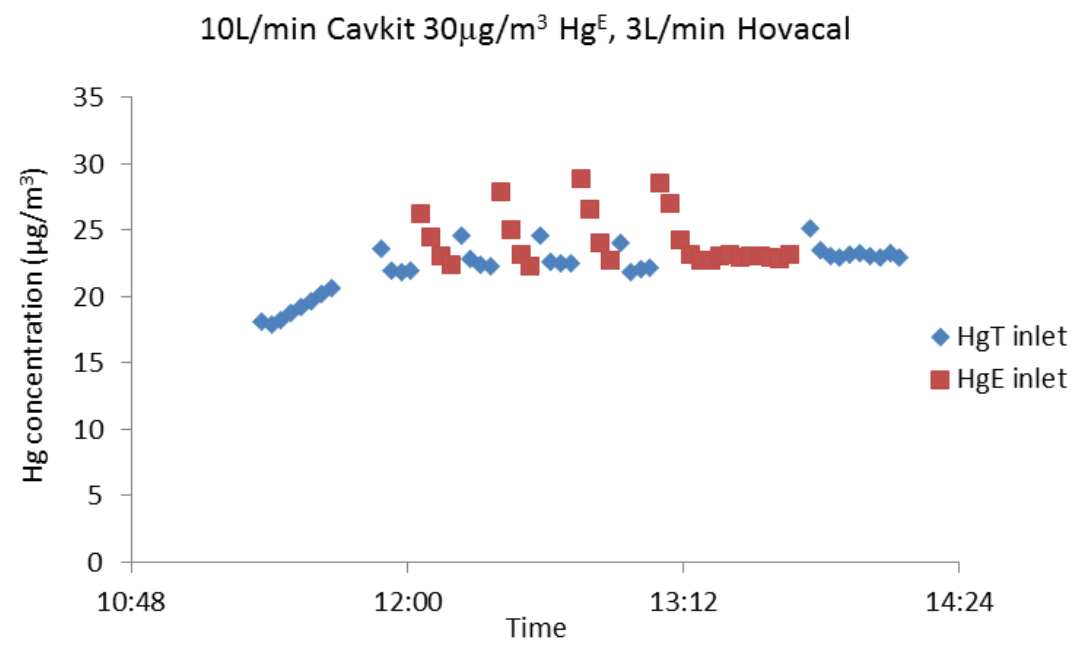

Figure 2 Sample Validation Process for Mercury Injection $\left(\mathrm{Hg}^{\mathrm{T}}\right.$ in blue, $\mathrm{Hg}^{\mathrm{E}}$ in red $)$ 


\section{Macrothink}

The experiment shown in Figure 2 had only elemental mercury $\left(\mathrm{Hg}^{\mathrm{E}}\right)$ from Cavkit along with a dilution air stream. No $\mathrm{CO}_{2}$ or liquid solution was introduced. One important characteristic of all the mercury measurements is the 10-minute, or more, response time required for a steady result after the measurement was switched from one channel to another. The peaks in concentration can be explained by the release of accumulated mercury as the pressure changes due to the different flow pathways. This does not indicate a different concentration through the system but only during the reading phase of the semi-continuous monitoring. In order to receive a stabilized signal, therefore, all of the mercury experiments were operated over much longer times.

\subsubsection{Elemental Mercury Removal by Sodium Hydroxide Solution}

Figure 3 shows the capture performance during Test 1 conditions with only elemental mercury and sodium hydroxide. The initial gas composition was as noted. Gas residence time was 26 seconds. At 3:02 the $\mathrm{CO}_{2}$ stream was stopped and the HovaCal flow rate was raised to $5.25 \mathrm{~L} / \mathrm{min}$ to maintain the same total gas input. $\mathrm{CO}_{2}$ input was $14.75 \% . \mathrm{CO}_{2}$ output was $1.3 \%$, which indicated a $93 \%$ of removal for this case. Elemental mercury at the inlet was measured around $35 \mu \mathrm{g} / \mathrm{m}^{3}$, while outlet concentration decreased to $25 \mu \mathrm{g} / \mathrm{m}^{3}$. The elemental mercury removal rate was thereby calculated as $24 \%$. It can also be clearly seen that there was no influence on mercury removal from the change in $\mathrm{CO}_{2}$ concentration. This justifies the approach of measuring the mercury capture independent of $\mathrm{CO}_{2}$ capture as long as the same operating conditions are maintained. The elemental mercury measurement at the inlet is made before and after the monitoring of the outlet mercury; the figure shows only the post measurement to demonstrate that there was no change in the mercury flow to the system during the test.

10L/min Cavkit HgE, 3L/min HovaCal, 2.25L/min $\mathrm{CO}_{2}$ 20 gal $0.5 \mathrm{~N} \mathrm{NaOH} 1.2 \mathrm{~L} / \mathrm{min}$

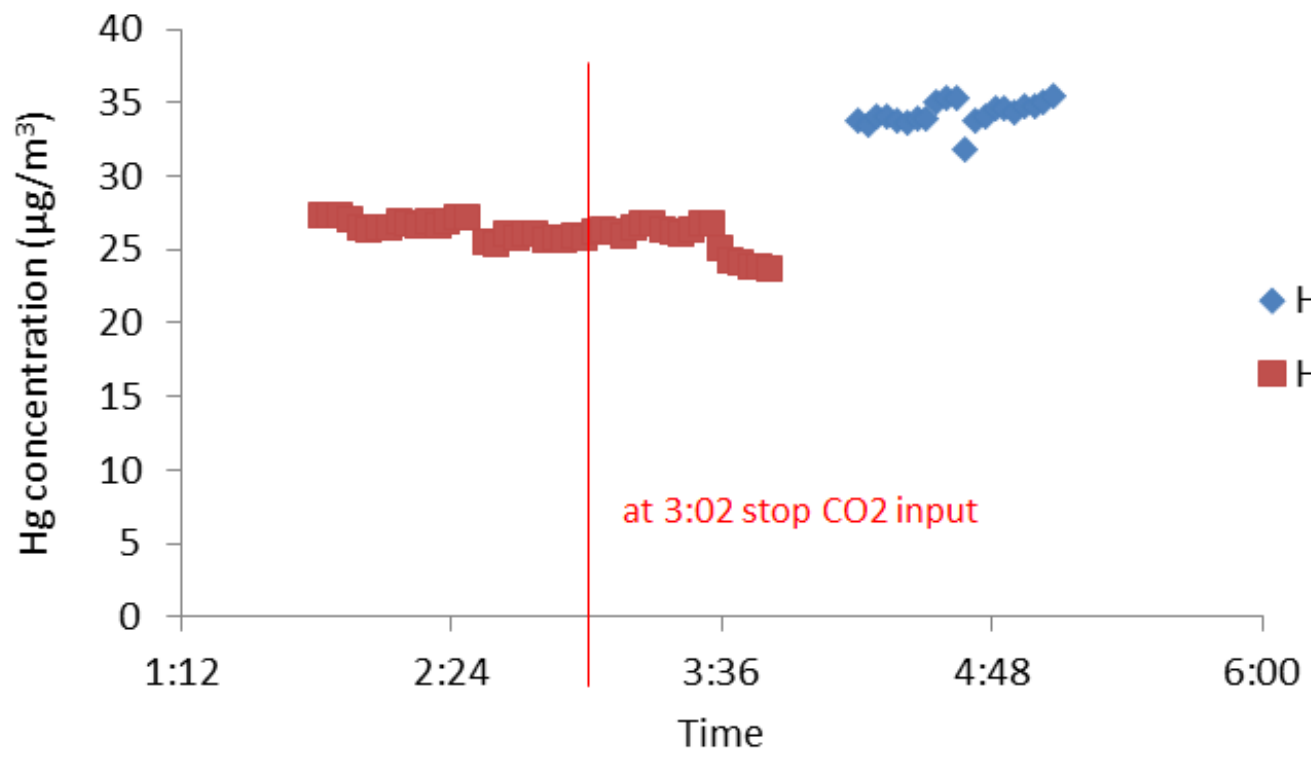

Figure 3 Test 1 of $\mathrm{HgE}$ Removal by $\mathrm{NaOH}$ Solution 


\section{Macrothink}

Test 2 conditions were run with exactly the same parameters as in the latter part of the Test 1 case without $\mathrm{CO}_{2}$. The result suggested that $34 \mu \mathrm{g} / \mathrm{m}^{3}$ of elemental mercury input was reduced to $25 \mu \mathrm{g} / \mathrm{m}^{3}$ at the scrubber exit. The elemental mercury removal rate of $26 \%$ was similar to that obtained with Test 1 conditions. This test was repeated, as Test 3, at an elevated elemental mercury input level of $40 \mu \mathrm{g} / \mathrm{m}^{3}$. The removal rate was $18 \%$. This conversion rate deviated a bit from the rate found from Test 1 and 2 conditions, but the variation is not dramatic. The difference may be due to the higher inlet mercury condition or mercury adsorption to scrubber surfaces.

\subsubsection{Oxidized Mercury Removal by Sodium Hydroxide Solution}

Figure 4 shows the oxidized mercury removal Test 4 with only $\mathrm{HgCl}_{2}$ input by the HovaCal. The standard solution for the HovaCal was prepared with reagent solid $\mathrm{HgCl}_{2}$ and $\mathrm{HCl}$ solution as a stabilizer, which can prevent the reduction of $\mathrm{Hg}^{2+}$ to elemental $\mathrm{Hg}$ during storage (Interim EPA Traceability Protocol for Qualification and Certification of Oxidized Mercury Gas Generators, 2009). Even with this precaution, a small portion of the oxidized mercury was converted to elemental mercury through the system. In Test 4 at the inlet a low level of $6 \mu \mathrm{g} / \mathrm{m}^{3}$ of $\mathrm{Hg}^{\mathrm{E}}$ was measured, which remained almost the same at the outlet. Because total and elemental mercury are the two directly detected signals by the mercury atomic fluorescence detector, the oxidized mercury concentration needs to be translated with the average of these two concentrations, instead of shown directly as recorded. With this correction, during the Test 4 run the $\mathrm{Hg}^{2+}$ concentration drops from $37 \mu \mathrm{g} / \mathrm{m}^{3}$ to $2 \mu \mathrm{g} / \mathrm{m}^{3}$, indicating a promising removal rate of $95 \%$.

\section{L/min Cavkit, $3 \mathrm{~L} / \mathrm{min}$ HovaCal with $\mathrm{HgCl}_{2}$ $2 \mathrm{~L} / \mathrm{min} \mathrm{CO}_{2}, 1.3 \mathrm{~L} / \mathrm{min} \mathrm{NaOH}$}

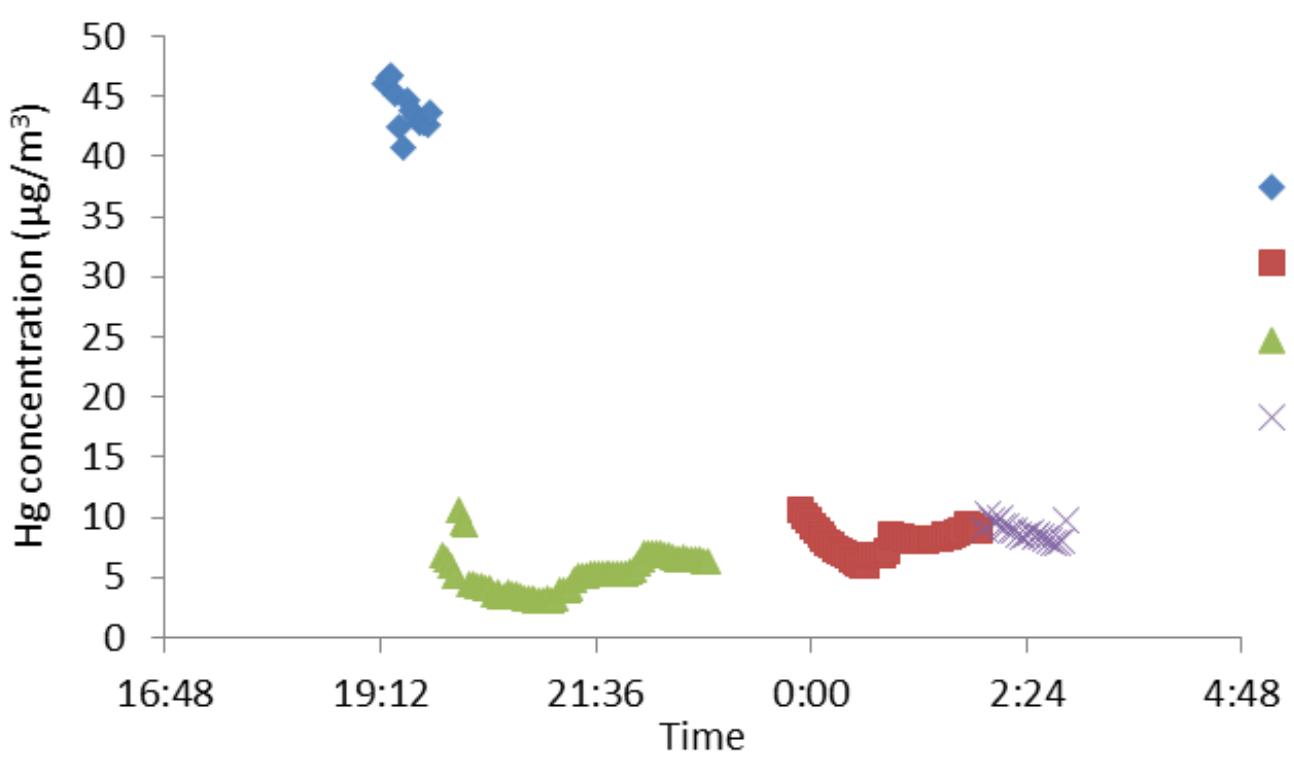

Figure 4 Test 4 of $\mathrm{Hg}^{2+}$ Removal by $\mathrm{NaOH}$ Solution 


\subsubsection{Mixed Mercury Removal by Sodium Hydroxide Solution}

10L/min Cavkit $30 \mu \mathrm{g} / \mathrm{m}^{3} \mathrm{Hg}^{\mathrm{E}}, 3 \mathrm{~L} / \mathrm{min}$ HovaCal with $\mathrm{HgCl}_{2}$ $2 \mathrm{~L} / \mathrm{min} \mathrm{CO}_{2}, 20 \mathrm{gal} 0.5 \mathrm{~N} \mathrm{NaOH} 1.2 \mathrm{~L} / \mathrm{min}$

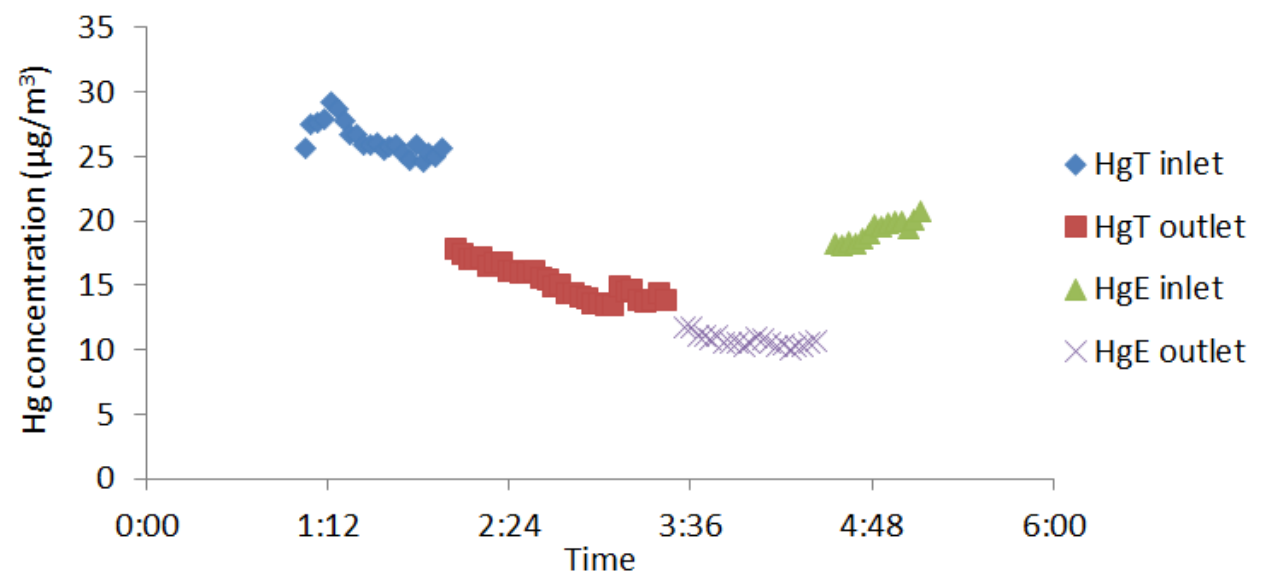

Figure 5 Test 5 of $\mathrm{Hg}^{\mathrm{E}}$ and $\mathrm{Hg}^{2+}$ Removal by $\mathrm{NaOH}$ Solution

In Test 5 and 6 both elemental mercury and oxidized mercury were introduced to the scrubber. Elemental mercury was measured at $20 \mu \mathrm{g} / \mathrm{m}^{3}$ and $11 \mu \mathrm{g} / \mathrm{m}^{3}$ at inlet and outlet, respectively, during Test 5 (shown in Figure 5). Oxidized mercury had a reading of $5 \mu \mathrm{g} / \mathrm{m}^{3}$ at the inlet and $4 \mu \mathrm{g} / \mathrm{m}^{3}$ at the outlet. The removal efficiency for elemental mercury was $45 \%$ and for oxidized mercury as $20 \%$. These two values seem suspicious, especially the oxidized mercury removal rate because of the relatively large deviation from the independent measurement described in the prior section, though the absolute concentration was substantially lower. Consequently, Test 6 was run with a specific objective of verifying the system performance and identifying sources of unexpected results.

10L/min Cavkit $30 \mu \mathrm{g} / \mathrm{m}^{3} \mathrm{HgE}, 3 \mathrm{~L} / \mathrm{min}$ HovaCal with $\mathrm{HgCl}_{2}$

$2.25 \mathrm{~L} / \mathrm{min} \mathrm{CO}_{2}, 20 \mathrm{gal} 0.5 \mathrm{~N} \mathrm{NaOH} 1.2 \mathrm{~L} / \mathrm{min}$

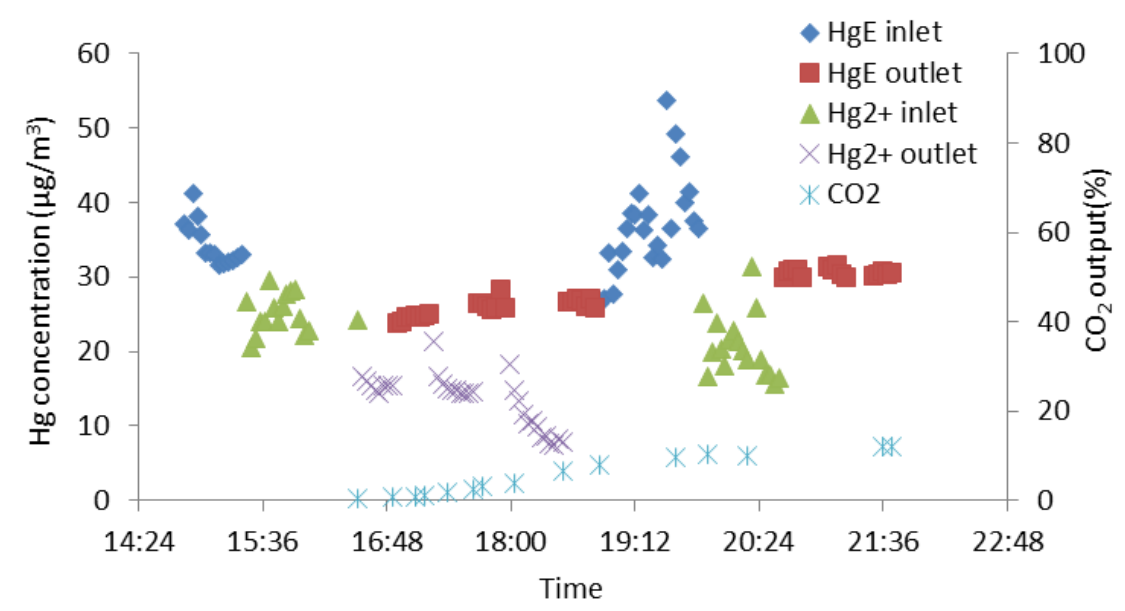

Figure 6 Test 6 of $\mathrm{Hg}^{\mathrm{E}}$ and $\mathrm{Hg}^{2+}$ Removal by $\mathrm{NaOH}$ Solution 
Results of Test 6 are plotted in Figure 6. The figure shows the converted oxidized mercury concentration directly for easier reading. Even though the data appears scattered, they are reasonable based on the expected variations over a prolonged operation time. Several system adjustments were performed during the experiment, i.e. emptying accumulated liquid in the liquid-gas separator, verifying constant pump pressure head, and etc. All of these cause some fluctuations of the signal. Attention needs to be paid when analyzing the oxidized mercury outlet concentration. There were three segments of data, which were interrupted by switching with the elemental mercury outlet measurement. The first two segments were not long enough and were terminated too early by the $\mathrm{Hg}^{\mathrm{E}}$ measurement at the outlet. After seeing the concentration was higher than expected, the third segment of measurement was purposely prolonged. There was clearly a drop of $\mathrm{Hg}^{2+}$ concentration during that period. A longer test can result in the possible fouling of the mercury dry speciation module, leading to a slower measurement response time. By comparing the trends of these three segments, the end of the third segment was more representative of the actual oxidized mercury concentration at the outlet. Another drawback of a longer test is the system contamination, which raises the background mercury level. Based on experience, a normal elevated background mercury level is around $7 \mu \mathrm{g} / \mathrm{m}^{3}$. This concentration does not play an important role when the actual level is much higher. However, if the actual concentration is close or lower than the background, it can confuse the measurement. Therefore, the oxidized mercury output concentration was adjusted to $3 \mu \mathrm{g} / \mathrm{m}^{3}$. Input concentration for $\mathrm{Hg}^{2+}$ remained $25 \mu \mathrm{g} / \mathrm{m}^{3}$. A removal efficiency of $88 \%$ was obtained. Elemental mercury concentrations were $33 \mu \mathrm{g} / \mathrm{m}^{3}$ and $26 \mu \mathrm{g} / \mathrm{m}^{3}$ for input and output, correspondingly. Elemental mercury was captured at about $21 \%$. $\mathrm{CO}_{2}$ output concentration gradually increased from $1 \%$ to $12.2 \%$, when the input value was $14.75 \%$, as the capture base was depleted.

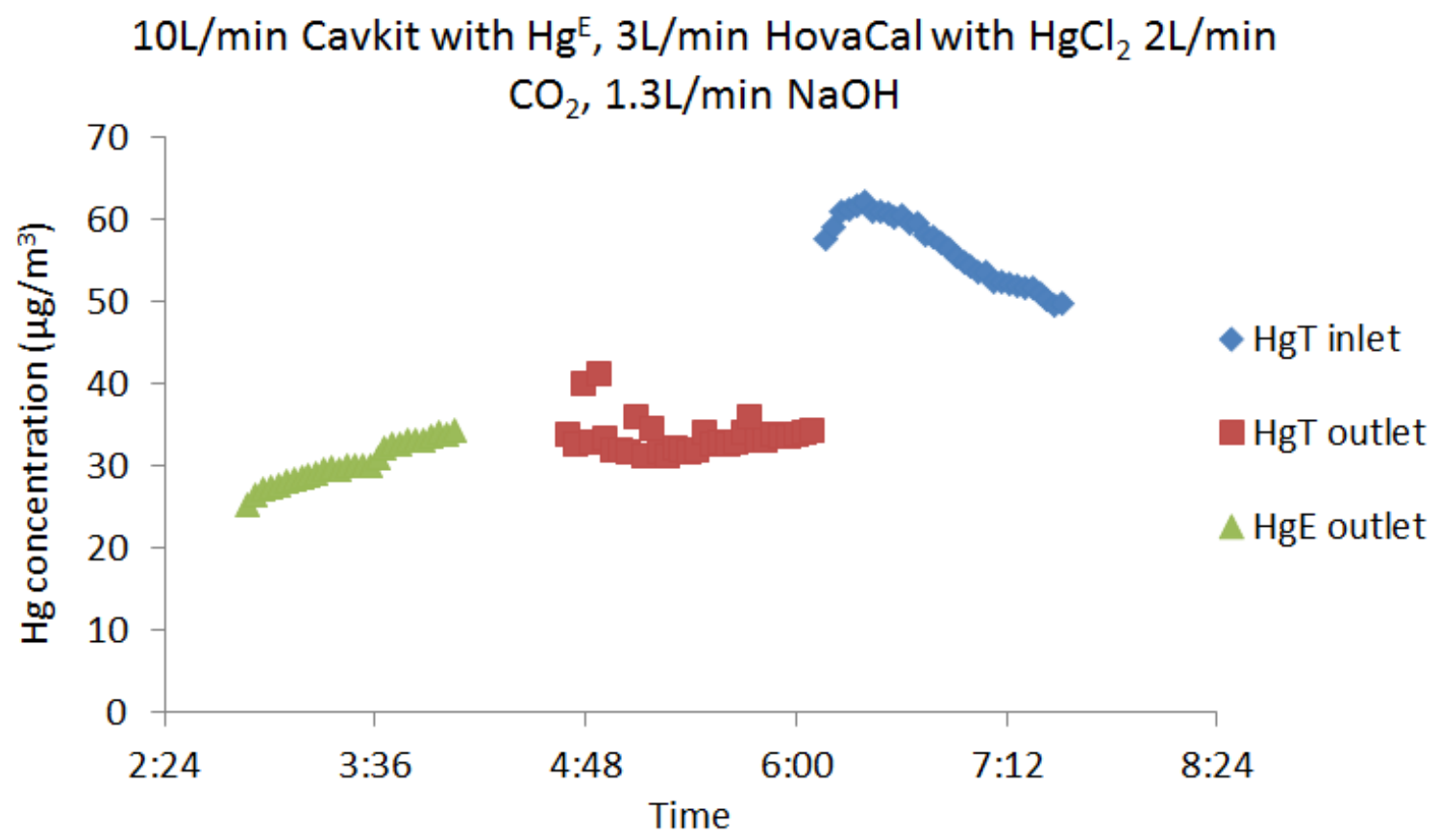


Figure 7 Test 7 of $\mathrm{Hg}^{\mathrm{E}}$ and $\mathrm{Hg}^{2+}$ Removal by $\mathrm{NaOH}$ Solution

Test 7, shown in Figure 7, was operated under the same conditions as Test 6. The elemental mercury input concentration was $33 \mu \mathrm{g} / \mathrm{m}^{3}$, but for clarity is not included in the figure. The output concentration did not change too much and measured $30 \mu \mathrm{g} / \mathrm{m}^{3}$. Oxidized mercury concentration was determined as $2 \mu \mathrm{g} / \mathrm{m}^{3}$ at the outlet and $20 \mu \mathrm{g} / \mathrm{m}^{3}$ at inlet. Removal efficiency was $95 \%$, which agreed with Test 4 and 6.

Table 1 summarizes the results collected from all mercury tests. It can be seen that the mercury removal rates for both elemental and oxidized forms were repeatable. $\mathrm{NaOH}$ removed an average of $20 \%$ of elemental mercury and $90 \%$ of oxidized mercury under conditions favorable for $\mathrm{CO}_{2}$ capture. This efficacy is very similar to that of FGD systems reported by other researchers (Rhudy, 2007) (Chu, 2000) (Babcock \& Wilcox company, 2002). These findings are mostly due to the different solubility of mercury species. The strong basic nature of the solution does not affect this unfortunate condition. Adsorption to instrument surfaces accounts for most of the removed $\mathrm{Hg}^{\mathrm{E}}$ from the gas stream. However, the surface bond is weak, which can result in desorption of the trapped mercury, as shown in some tests. No influence from $\mathrm{CO}_{2}$ was noticed for all runs.

Table 1 Summary of Mercury Removal Tests Performance

\begin{tabular}{|c|c|c|c|c|c|c|c|}
\hline \multirow[b]{3}{*}{ Test } & \multirow[b]{2}{*}{ Reagent } & \multicolumn{3}{|c|}{$\mathbf{H g}^{\mathrm{E}}$} & \multicolumn{3}{|c|}{$\mathbf{H g}^{2+}$} \\
\hline & & Input & Output & Removal & Input & Output & Removal \\
\hline & $0.5(\mathrm{~mol} / \mathrm{L})$ & $\left(\mu \mathrm{g} / \mathrm{m}^{3}\right)$ & $\left(\mu \mathrm{g} / \mathrm{m}^{3}\right)$ & $(\%)$ & $\left(\mu \mathrm{g} / \mathrm{m}^{3}\right)$ & $\left(\mu \mathrm{g} / \mathrm{m}^{3}\right)$ & $(\%)$ \\
\hline 1 & $\mathrm{NaOH}$ & 34 & 26 & 24 & $-^{2}$ & - & - \\
\hline 2 & $\mathrm{NaOH}$ & 34 & 25 & 26 & - & - & - \\
\hline 3 & $\mathrm{NaOH}$ & 40 & 33 & 18 & - & - & - \\
\hline 4 & $\mathrm{NaOH}$ & - & - & - & 37 & 2 & 95 \\
\hline $5^{*}$ & $\mathrm{NaOH}$ & 20 & 11 & 45 & 5 & 4 & 20 \\
\hline 6 & $\mathrm{NaOH}$ & 33 & 26 & 21 & 25 & 3 & 88 \\
\hline 7 & $\mathrm{NaOH}$ & 33 & 30 & 9 & 25 & 1 & 96 \\
\hline
\end{tabular}

* suspicious due to relatively big deviation for low concentration

Clear findings were obtained in this study. It can be concluded that the CMAP process (and similar precipitation based strategies for $\mathrm{CO}_{2}$ sequestration) has comparable mercury removal efficiency to that of standard FGD devices. The process is effective at removing oxidized mercury with $\mathrm{CO}_{2}$ at the same time without any modification. However, since liquid analysis was not performed in this study, it is unclear about the actual form of the oxidized mercury species in the solution. Like FGD systems, the CMAP process does not capture elemental mercury very well. It appears likely that additional methods will be needed in order to facilitate oxidation of elemental mercury or that activated carbon will need to be injected 
upstream of the scrubber to enhance elemental mercury capture (Nolan, 2004) (Chang, Development and demonstration of mercury control by dry technologies, 2005) (Chang, Status of mercury control technologies: acrivated carbon injection and boiler chemical additives, 2006).

\subsection{Liquid Phase Mercury Simulation}

To better understand and interpret the experimental results, a thermodynamic equilibrium calculation was done using Visual MINTEQ. Visual MINTEQ is a freeware chemical equilibrium model for the calculation of metal speciation, solubility equilibria, sorption, and other properties for natural waters. It combines state-of-the-art descriptions of sorption and complexation reactions with easy-to-use menus. The code, originally built on USEPA's MINTEQA2 software, has been maintained by Jon Petter Gustafsson at KTH, Sweden, since 2000 (Visual MINTEQ, n.d.) (Allison, 1991).

Table 2 Modeling with Visual MINTEQ

\begin{tabular}{|c|c|c|c|c|c|c|c|c|}
\hline \multicolumn{3}{|l|}{ Run } & 1 & 2 & 3 & 4 & 5 & $6^{*}$ \\
\hline \multirow{5}{*}{$\vec{\Xi}$} & $\mathrm{NaOH}$ & $\mathrm{mol} / \mathrm{L}$ & 0.5 & 0.5 & 0.5 & 0.5 & 0.5 & $\begin{array}{l}0.5 \\
\left(\mathrm{Na}_{2} \mathrm{CO}_{3}\right)\end{array}$ \\
\hline & $\mathrm{CO}_{2}$ & $\%$ & 15 & 0 & 15 & 0 & 15 & 15 \\
\hline & $\mathrm{O}_{2}$ & $\%$ & 17 & 21 & 17 & 21 & 17 & 0 \\
\hline & $\mathrm{Hg}^{\mathrm{E}}$ & $\mathrm{ppb}$ & 4.47 & 4.47 & 0 & 0 & 4.47 & 4.47 \\
\hline & $\mathrm{HgCl}_{2}$ & $\mathrm{~mol} / \mathrm{L}$ & 0 & 0 & $1.42 \mathrm{E}-08$ & $1.42 \mathrm{E}-08$ & $1.42 \mathrm{E}-08$ & 0 \\
\hline \multicolumn{2}{|c|}{ Total dissolved $\mathrm{Hg}^{+}$} & $\mathrm{mol} / \mathrm{L}$ & $1.81 \mathrm{E}-05$ & $2.02 \mathrm{E}-05$ & $1.00 \mathrm{E}-16$ & $1.00 \mathrm{E}-16$ & $1.81 \mathrm{E}-05$ & $9.95 \mathrm{E}-11$ \\
\hline \multicolumn{2}{|c|}{$\mathrm{Hg}^{\mathrm{E}}(\mathrm{aq})$} & $\%$ & 0.007 & 0 & 86.346 & 85.406 & 0.007 & 100 \\
\hline \multicolumn{2}{|l|}{$\mathrm{Hg}^{+}$} & $\%$ & 99.993 & 100 & 13.654 & 14.594 & 99.993 & 0 \\
\hline \multicolumn{2}{|c|}{ Total dissolved $\mathrm{Hg}^{2+}$} & $\mathrm{mol} / \mathrm{L}$ & - & - & $1.42 \mathrm{E}-08$ & $1.42 \mathrm{E}-08$ & $1.42 \mathrm{E}-08$ & - \\
\hline \multicolumn{2}{|c|}{$\mathrm{Hg}\left(\mathrm{CO}_{3}\right)_{2}{ }^{2-}$} & $\%$ & - & - & 40.939 & & 40.939 & - \\
\hline \multicolumn{2}{|c|}{$\mathrm{Hg}(\mathrm{OH})_{2}$} & $\%$ & - & - & 9.624 & 100 & 9.624 & - \\
\hline \multicolumn{2}{|c|}{$\mathrm{HgCO}_{3}(\mathrm{aq})$} & $\%$ & - & - & 1.997 & & 1.997 & - \\
\hline \multicolumn{2}{|c|}{$\mathrm{HgOHCO}_{3}^{-}$} & $\%$ & - & - & 47.2 & & 47.2 & - \\
\hline \multicolumn{2}{|c|}{$\mathrm{HgClOH}(\mathrm{aq})$} & $\%$ & - & - & 0.237 & & 0.237 & - \\
\hline
\end{tabular}

*Only Visual MINTEQ simulation without experiment 
Total dissolved $\mathrm{Hg}^{+}=\mathrm{Hg}^{\mathrm{E}}(\mathrm{aq})+\mathrm{Hg}^{+}$

Total dissolved $\mathrm{Hg}^{2+}=$ sum of all species on right and etc.

Run number refers to number designated in simulation matrix

The simulation input matrix for this numerical study is listed in Table 2. It covers all of the testing conditions that have been investigated experimentally. The $\mathrm{CO}_{2}$ concentration was rounded to $15 \%$ for easier comparison. Atmospheric $\mathrm{O}_{2}$ concentration of $21 \%$ was reduced to $17 \%$ when mixed with $\mathrm{CO}_{2}$. Because Visual MINTEQ only predicts the equilibrium situation, it could not handle real-time absorption. At equilibrium, elemental mercury was considered to be in the gaseous phase with a constant input concentration of $40 \mu \mathrm{g} / \mathrm{m}^{3}$, which is high enough to not be affected by the absorption process. Due to the high solubility of oxidized mercury, it was dissolved $100 \%$ into the liquid phase as an input. The concentration was assumed to match a continuous running of the system at $40 \mu \mathrm{g} / \mathrm{m}^{3}$ of $\mathrm{Hg}^{2+}$ after 3 hours, which resulted in a concentration of $1.42 \mathrm{E}-08 \mathrm{~mol} / \mathrm{L}$ in solution. These initial inputs were then calculated by Visual MINTEQ to determine how much elemental mercury would expect to be absorbed based on solubility, if any mercury species will evaporate or precipitate, and what is the speciation between dissolved mercury forms at the final state.

Several things need to be noted before interpreting the result. The total dissolved $\mathrm{Hg}^{+}$has two forms according to Visual MINTEQ, $\mathrm{Hg}^{\mathrm{E}}(\mathrm{aq})$ and $\mathrm{Hg}^{+}$, even though $\mathrm{Hg}^{\mathrm{E}}$ is in the elemental state with no charge. Total dissolved oxidized mercury had over a dozen chemical formations by the end of equilibrium; hence, only the most concentrated five species are shown (they account for over $99.99 \%$ of the total oxidized mercury).

It is clear that $\mathrm{Hg}^{2+}$ was $100 \%$ absorbed into liquid (absolute concentration of the total dissolved $\mathrm{Hg}^{2+}$ equals to the input value). When analyzing the total dissolved $\mathrm{Hg}^{+}$, special attention should be paid to the speciation of dissolved species. By comparing the results from Run 1 and 6, it can be seen that the oxidation of elemental mercury is predominantly by the oxygen dissolved into the liquid phase. In Run 1, for example, the concentration of the dissolved $\mathrm{Hg}(\mathrm{aq})$ is actually $1.27 \mathrm{E}-9 \mathrm{~mol} / \mathrm{L}$, which is already ten times lower than the dissolved $\mathrm{Hg}^{2+}$. When oxygen is absent, like in Run 6, this concentration drops to $9.9528 \mathrm{E}-11 \mathrm{~mol} / \mathrm{L}$, which suggests essentially no mercury removal capacity. Therefore, the system has low removal efficiency on elemental mercury, of which physical adsorption accounts for a large portion. This corresponds with the experimental results very well. The discrepancy showed in the total dissolved $\mathrm{Hg}^{+}$by Visual MINTEQ is believed because of the thermodynamic equilibrium nature of the simulation, which lacks kinetics to deal with slow reactions.

Runs with and without $\mathrm{CO}_{2}$ showed that there is no significant interference with $\mathrm{CO}_{2}$, i.e. run 1 and 2, which is also consistent with the experimental findings. $\mathrm{CO}_{2}$ ratio only changed the speciation of $\mathrm{Hg}^{2+}$ by increasing carbonate related mercury species.

Visual MINTEQ equilibrium modeling confirmed the removal efficiency received from experiments and suggested speciation in liquid solution. However, due to lacking of kinetics, it could not provide any information on slow reactions such as the oxidation and absorption 
of elemental mercury.

\section{Acknowledgement}

This work was supported by UC Discovery Grant, \#180881, University of California. The author would like to thank Jamie Bresson at Calera Corporation. He has made available his support in a number of ways from reactor design to operating conditions of relevance.

\section{References}

(n.d.). From Visual MINTEQ: http://www2.lwr.kth.se/English/OurSoftware/Vminteq/

Air pollution prevention and control division, U.S. Environmental Protection Agency. (n.d.). Control of mercury emissions from coal-fired eletric utility boilers. Research Triangle Park, NC.

Allison, J. D. (1991). MINTEQA2/PRODEFA2, A geochemical assessment model for environmental systems: version 3.0 users' manual. EPA.

Aroonwilas, A. (1999). Behavior of the mass-transfer coefficient of structured packings in CO2 absorbers with chemical reactions. 38, 20442050.

Aroonwilas, A. (2003). Mathematical modelling of mass-transfer and hydrodynamic in CO2 absorbers packed with structured packings. 58, 4037-4053.

Babcock \& Wilcox company. (2002). Full-scale testing of enhanced mercury control technologies for wet FGD systems.

Chang, R. (2005). Development and demonstration of mercury control by dry technologies. EPRI.

Chang, R. (2006). Status of mercury control technologies: acrivated carbon injection and boiler chemical additives. EPRI.

Chu, P. (2000). An assessment of mercury emissions from U.S. coal-fired power plants. EPRI.

Clarke, L. B. (1992). The fate of trace elements during coal combustion and gasification: an overview. 72(6).

Constantz, B. R. (n.d.). US/Los Gatos Patent No. USPC Class: 423230.

Diaz-Somoano, M. (2007). Mercury emission control in coal-fired plants: The role of wet scrubbers. 88. http://dx.doi.org/10.1016/j.fuproc.2006.10.003

(2002). Global mercury assessment. United Nations Environment Programme, Chemicals. Geneva, Switzerland.

Hance, S. B. (1991). Status of flue gas desulfurization systems. 84th Annual meeting of the air and waste management association.

(2009). Interim EPA Traceability Protocol for Qualification and Certification of Oxidized 
Mercury Gas Generators.

Kolker, A. (2006). Mercury in coal and the impact of coal quality on mercury emissions from combustion systems. Applied Geochemistry, 21, 1821-1836. http://dx.doi.org/10.1016/j.apgeochem.2006.08.001

Laudal, D. (2000). Effects of flue gas constituents on mercury speciation. Fuel Processing Technology, 65-66, 157-165. http://dx.doi.org/10.1016/S0378-3820(99)00083-1

Lee, S. (206). Speciation and mass distribution of mercury in a bituminous coal-fired $\begin{array}{llll}\text { powerplant. Atmospheric } & \text { Environment, } & \text { 2215-2224. }\end{array}$ http://dx.doi.org/10.1016/j.atmosenv.2005.12.013

Leva, M. (1966). Gas absorption in beds of rings and saddles. 224-230.

Longwell, J. P. (1995). Coal: energy for the future. 21, 269-360. http://dx.doi.org/10.1016/0360-1285(95)00007-0

Meij, R. (2006). Mercury emissions from coal-fired power stations: The current state of the art in the Netherlands. Science of the Total Environment, 368, 393-396. http://dx.doi.org/10.1016/j.scitotenv.2005.09.083

(December 1997). Mercury Study Report to Congress, Volume I. United States Environmental Protection Agency.

Nolan, P. S. (2004). Demonstration of additive use for enhanced mercury emissions control in wet FGD systems. 85, 287-600. http://dx.doi.org/10.1016/j.fuproc.2003.11.009

Pacyna, J. M. (2000). Assessment of emissions/discharges of mercury reaching the arctic environment.

Park, K. (2008). Emission and speciation of mercury from various combustion sources. Powder Technology, 180, 151-156. http://dx.doi.org/10.1016/j.powtec.2007.03.006

Pavlish, J. (2003). Status review of mercury control options for coal-fired power plants. Fuel Processing Technology, 82, 89-165. http://dx.doi.org/10.1016/S0378-3820(03)00059-6

Rhudy, R. (2007). Update of enhanced mercury capture by wet FGD. EPRI.

Richards, G. M. (1963). Kinetics of CO2 absorption-III. 19, 325-328.

Richardson, J. F. (2002). Chemical Engineering: Particle Technology and Separation Processes (Vol. 2). Woburn, MA: Butterworth-Heinemann.

Tan, Y. (2004). An invertigation of mercury distribution and speciation during coal combustion. Fuel, 83, 2229-2236. http://dx.doi.org/10.1016/j.fuel.2004.06.015

Tontiwachwuthikul, P. (1992). $\mathrm{CO} 2$ absorption by $\mathrm{NaOH}$, Monoethanolamine and 2-amino-2-methyl-1-propanol solutions in a packed column. 47, 381-390. http://dx.doi.org/10.1016/0009-2509(92)80028-B

Yokoyama, T. (2000). Mercury emissions from a coal-fired power plant in Japan. The Science 


\section{Macrothink}

Environmental Management and Sustainable Development

ISSN 2164-7682

2015, Vol. 4, No. 2

of the Total Environment, 259, 97-103. http://dx.doi.org/10.1016/S0048-9697(00)00552-0

\section{Copyright Disclaimer}

Copyright for this article is retained by the author(s), with first publication rights granted to the journal.

This is an open-access article distributed under the terms and conditions of the Creative Commons Attribution license (http://creativecommons.org/licenses/by/3.0/). 